BULLETIN OF THE GEOLOGICAL SOCIETY OF AMERICA

VoL. 10, PP. 263-276.

APRIL 17, 1899

\title{
SPACING OF RIVERS WITH REFERENCE TO HYPOTHESIS OF BASELEVELING
}

BY N. S. SHALER

(Presented before the Society December 30, 1898)

\section{CONTENTS}

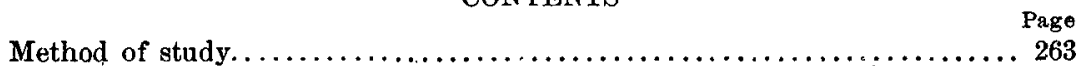

Author's first observations.............................. 263

Evidence furnished by topographic maps.................... 264

Value of studying beginnings of stream work $\ldots \ldots \ldots \ldots \ldots \ldots \ldots \ldots 264$

Conditions of small streams............................... $26 \tilde{s}$

Experiments with thin layers of water........................ 265

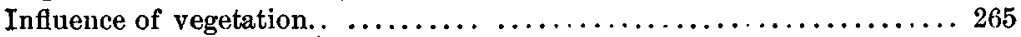

Effect of rain on smooth, sloping surfaces.................... 266

Drainage development and its application to study of river spacing ... 267

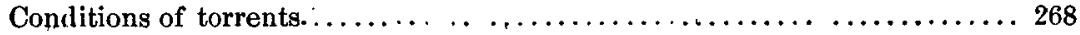

Relation of slope to down-cutting and basin area............... 268

Application of experiments and observations to study of natural condi-

tions .............................................. 269

Bearing of evidence on baseleveling.......................... 270

Relation of down-wearing to uniformity of level................ 270

Baselevels of the A ppalachians........................... 270

Problem of A ppalachian baseleveling. ...................... 273

Iiscussion of hypothesis of baseleveling and of river spacing. $\ldots \ldots \ldots \ldots \ldots 275$

\section{Method of Study}

\section{AUTHOR'S FIRST OBSERVATIONS}

A glance at any accurate maps will show that water-courses in nearly all regions are so disposed that they are somew hat regularly spaced, the intervals between their channels of like size being approximately the same even when the character of the rocks and the amount of the rainfall are somewhat varied. My attention was called to this fact some 20 years ago, when considering the relations of the rivers of Kentucky. While comparing the order of the under and over ground channels of that district I noted that while the cavern waters followed no distinct 
order in their placement, except such as was determined by the jointing of the limestone rocks in which they were excavated, the surface streams of the neighboring cavernless country were grouped with rather definite intervals which did not distinctly vary, whatever the character of the subjacent rock might be. A debate which occurred in the geological conference of Harvard University in 1897, on a paper presented by Professor Penck, of Vienna, showed me that this distinguished geographer had noted like facts in the Alps and in the Cordilleras, and indeed it must have attracted the attention of many observers. This revival of the inquiry has led me to the observations and inferences which are set forth below.

\section{EVIDENCE FURNISHED BY TOPOGRAPHIC MAPS}

First, let us note in a more detailed way the certain important facts concerning the placement of streams which has just been stated as a very general proposition. Taking a series of maps which show in an accurate manner the geological and topographical aspects of diversely conditioned areas, we may readily observe that on those areas which have been long and continuously exposed to the effective work of streams the spacing of the channels is in the greatest measure uniform. On the other hand, where, as in the coastal plain districts of the United States, the surface has recently risen from the sea, the intervals between the streams of all sizes is much more irregular. Again, in countries of inconsiderable reliefs which have had their former drainage system effaced by a deep coating of glacial drift the order of position of the newly determined channels has something like the irregularity which is exhibited by newly elevated area. The fact that the likeness and the order of streams is least evident where they have acted for the shortest time, and most so where they have been long in operation, suggests the hy pothesis that the distribution of their channels in an equable manner is in some way brought about by the action of the streams themselves; that in wearing downward they work in a manner which tends to equalize their intervals.

\section{VALUE OF STUDYING BEGINNIN'GS OF STREAM WORK}

Apparently the best method of approaching the discussion of the view just stated is by observing what takes place in those beginnings of streamwork which we may observe wherever a sloping. surface of earth has been exposed to the action of the rain. On such surfaces, as is well known, a drainage system in miniature is quickly developed, the channels at the beginnings of the process being very small and much branched, and the whole appearing, as has often been remarked, like a reduced model of a 
river system. By tracing the successive changes of these small temporary channels we may acquire much information as to what goes on in the slower but otherwise a pproximately similar process which takes place as the larger streams work downward into the rocks they traverse.

\section{Conditions of small Streams}

\section{EXPERIMENTS WITH THIN LAYERS OF WATER}

First, let us observe the conditions of the thin layer of water as it moves over a slightly tilted uniform surface such as a plate of glass. As the water is impelled by gravity to flow it shows an interesting tendency to gather into streams rather than to move as a sheet. Even the slight irregularities of the nearly perfect plane tends to create definite streamings. If now a thin coating of any fine somewhat adhesive material be placed on the plate, for instance, such as close grained clay, we note at once a distinct tendency to channeling-a drainage is in fact at once organized, the troughs of which will be rapidly deepened until the conditions of the rain-washed fields are essentially reproduced. It is thus made evident that the circumstances of movement of the thin layer of water which the rain brings to the sloping surfaces of the earth are such that very slight irregularities inevitably bring about the formation of distinct streams. If the earth were in a state to feel the effect of these tiny currents, it would, save in the very arid districts, be carved by channels so small that several would be traceable in each square foot. That such is not the case is due to the fact that almost everywhere the coating of vegetation is sufficiently dense to protect the soil from all except the considerable rivulets. It is only where a very great number of small temporary streams have combined to form a torrent that the energy of the moving water is sufficient to cut through the matted vegetation and to attack the soil.

\section{INFLUENCE OF VEGETATION}

While the existence of a vegetable coating in the natural field and its absence in the bared areas we are now considering is a noteworthy difference, one in certain ways affecting the value of the experiments, it does not really invalidate them. The effect of the plants is to limit the cutting action to much fewer streams-those, as above remarked, where the aggregated waters are able to brush away the mantle of vegetation. It thus comes about that there is commonly a broad field between the headwaters of adjacent rivers, which is protected from mechanical erosion by the fact that the lesser brooks can not attack the subjacent earth. In this way the formation of tablelands is favored, the destruction of the 
level areas being effected mainly by solutional processes until the retreating head escarpments of the larger streams work back across the surface of the upland. Notwithstanding these differences between the small and the great erosive work, the exhibitions of it which are afforded in the miniature stream systems throw much light upon true river action.

\section{EFFECT OF RAIN ON SMOOTH, SLOPING SURFACES}

In the first stage of rain work on a moderately smooth and gently sloping surface of bared earth we find the very numerous closely set little valleys before noted, such as may be produced in the course of half an hour of moderate rainfall. If we watch the further steps of the process we observe that as these channels cut deeper the valleys of some of them are widened, so that in an area where there was at first a dozen distinct grooves there is now perhaps but one. A change of this sort may at times be traced in the course of a few hours of continuous rain. It is, however, better seen during a season's changes which deepens valleys from the average depth of half an inch to that of a foot or more, with proportionate reduction in the number per unit of area.

Inspection of the process of change in the swiftly developing valleys of bared earth at once shows that the increase in the size of the channel is brought about by a process in which certain of the streams cut down and laterally with greater rapidity than the others. This process of development is in its nature and methods one of selection; it more clearly resembles the principle of the survival of the fittest than any other known to me in the inorganic realm. The reason for this likeness is to be found in the fact that in the mechanical changes of the streamlet, as in those of the living form, success is determined by the adjustment of the action to exceedingly varied conditions. In each we have something like a continuity of endeavor with the limitation which circumstances put upon it. In the institution of a very small drainage system, such as we are considering, the first action is determined by the currents which set up in the sheet of water before it begins to cut. The initial channels are in effect a map of these original streams. As soon as scouring begins those guiding features arising from the diversities of the surface and of the initial cutting power of the streams at once gives some of them the mastery. 'To perceive the value of these differences we should note that the cutting kower of the currents increases in a very high ratio to their speed, certainly as the square thereof, and perhaps in a much higher function. The result is that, given a very slight preponderance in size of one stream among many, this advantage will cause its channel to cut down more rapidly than do those of its competitors. As it extends its drainage slopes from its rapidly lowered base it inevitably captures the valleys 
from its smaller neighbors. This process, with minor variations in the method of work, goes on until the divides of the valley are forced back to a point where they encounter those of another stream which is doing similarly effective work.

DRAINAGE DEVELOPMENT AND ITS APPLICATION TO STUDY OF RIVER SPACING

In the advancing stages of drainage development in the natural model we are considering we find the process of lateral appropriation of the smaller channels is brought about in at least three ways: $(a)$ As the channel is deepened the side slopes of the valley keep their original angle of declivity, and thus invade the basins on either side; these, by reason of the reduction of the d rainage thereby brought about, work downward with less rapidity. (b) The lateral shifting of the streams as they are blockaded by the less movable waste also causes them here and there to invade the drainage of their neighbors. (c) Lastly, the peculiar process termed "piracy" occurs--that is, the small branches of the larger main stream work back through the divides until they tap and divert the adjacent higher lying water-courses. In a word, all the methods by which an ordinary river extends its field of drainage are fairly well represented in the miniature stream system.

If with these observations in mind the student proceeds to inquire concerning the difficult question as to the equal spacing of river channels of like size, he will find the explanation he seeks. He will note that the slopes of the drainage basins are, as regards their angles of declivity, quite as uniform as are their spacings; all of them meet in sharp crests, the divides between several valleys. These crests, as well as the lowlands, are wasting; but while the streams cut down freely, the crest lines descend at a slower rate. As long as the streams on either side of the divide work their beds downward with equal rapidity the ridge maintains its position; but if one descends more slowly than the other, then, as the slopes of their valleys are uniform, the deeper lying river pushes the crest back, thereby capturing a part of the watershed of its neighbor, with the result that the diminished valley will be less rapidly worn down than before, and therefore the more easily destroyed by the vigorous contestant. In this way it comes about that the lesser velleys are apt to be ruined by the development of the greater adjacent excavations. There is, however, as before noted, a limit to this action, which is set by the fixed angle of the side slopes of the valleys. This is determined by the character of the material which is wearing away. In the miniature example this wearing is purely erosive, and is commonly rather even in rate, for the reason that the soil is likely to be of a uniform composition. It is different in the case of ordinary river valleys, but 
the difference does not affect the principle involved, which is that the effective angle of the side slopes of the basin goes far to determine the limits of its lateral extension.

\section{CONDITIONS OF TORRENTS}

\section{RELATION OF SLOPE TO DOWN-CUTTING AND BASIN AREA}

With the principle last noted, that the declivity of a basin's slopes determines the range of its capturing, in mind, seeing also that the relative rate of down-cutting of the channel established the condition of the stream as winning or losing in drainage area, let us further consider the conditions which determine this down-cutting. In the first stages of the excavating work the miniature stream cuts very freely, the restraints of its baselevel not being felt. In a word, it is a torrent. As its bed grows deeper this influence begins to come in. The result is that the stream soon passes the stage in which it is gaining in volume by capturing drainage. Such augmentation as it receives in the later stages of downcutting are not likely to add much to its drainage area. Bearing in mind the fact concerning this loss of power, namely, that the speed is about as the square of the declivity and the efficient carrying energy as a higher function of the speed, we may readily perceive that a very sudden arrest is put to the capacity of the current to cut its bed deeper when it attains a certain diminution of slope.

It should now be possible to see why the rivulets on a considerably eroded surface of an originally even slope, however irregular they may be at the beginning, come to be rather evenly spaced in the course of their development. This spacing is in effect determined by the maximum depth to which the beds of the streams can cut down in a given time. Those channels which attain that depth do so because they manage to carry their load of debris beyond the field. If the waste is fed in too rapidly the cutting down is hindered. If they cut down to a certain grade they attain a critical point due to the diminished slope, beyond which they can not well become deeper. The result of these several equations of action is the establishment of a somewhat definite maximum area of basin, beyond the limits of which a stream can not effectively compete with its neighbors.

The conditions which make for the establishment of approximately equal intervals between the drainage channels may be fairly well illustrated by pressing down V-shaped blocks of equal size into a sheet of mud so as to make valleys of like dimensions. Imagine, now, that there is an arrest of the down-sinking of any valley as it comes to a certain critical plane the equivalent of the baselevel of erosion, and that the side slopes of the trough have the same declivity; it should at the same time 
be borne in mind that wherever a stream fails to work downward as rapidly as that of the adjacent channels, its drainage is invaded by the extension of the side slopes of its competitors, with the result that it still further loses its capacity to hold its original down-cutting power, its area being soon shared in something like equal measure by the more successful streams. The further this process continues the more complete the work of effacing the original irregularities of interval.

\section{APPLICATION OF EXPERIMENTS AND OBSERVATIONS TO STUDY OF NATURAL CONDITIONS}

If from these observations on the convenient miniature specimens, showing the conditions under which drainage channels are established and developed, we turn to the larger examples of such work, as are exhibited in river systems, we note at once the advantage of approaching our problem in the manner which has been pursued. In the first place, we see that the equality of the spacings in the larger streams is most perfect in those which in size and character nearly approach the small temporary gullies of newly bared soil. The torrent gorges which are cut in uniformly yielding rock are often as accurately spaced as in the smaller samples, though they may have the depth of hundreds of feet and an average width of a mile or more. As we pass to the true rivers the symmetry becomes less and less perfect as they increase in size. It may be said that in proportion as the grade of the side slopes leading to the divide diminishes and becomes thereby less regular, the spacing becomes less even.

The reason for the less regular intervals between the valleys of gentle declivity and moderate side slopes and those of rapid fall with steep slopes are numerous. Among them we may note the following: As the stream approaches its baselevel it is proportionately more and more affected by various influences which tend to deflect it from the center of its valley. Obstacles which should have been disregarded or easily overcome while the descent was steep now control its movement. 'This causes the lateral extension of the valley to be forced this way or that; it no longer, as before, induces the attack on the adjacent slopes to be tolerably uniform. In the basins of gentle descent the nature of the underlying rock is likely to play a more important part in controlling the topography and the share of solutional action greater than is the case in the torrential valleys. It is also to be noted that in districts which are underlaid by limestones, except they be dolomites, where the position of streams may be fixed by the formation of underground water-courses, which in the course of time become open channels, the arrangement of the streams is often extremely irregular. In such case their order is determined by the 
jointing of the rocks and other details of structure and attitude which do not have controlling influence on surface rivers.

The foregoing considerations concerning the spacing of rivers, though in themselves matters of interest, as they point the way to a clear understanding of important geological problems, bave a much wider application than appears at first sight. I shall now endeavor to show that they may bear on the question as to the origin of the coincidences in mountain crests, which is so generally held to indicate the existence of ancient baselevels of erosion which have been lifted to a hight above the level of the sea and then dissected by rivers. To perceive the value of these indications we must again revert to the facts shown in the miniature valley. It is noticeable that the divides between these streams are often maintained in about the same plane to whatever depth the general surface may be lowered. I have seen instances of it where the valleys had cut down to a depth greater than their width. This element of regularity is quite as evident as the uniformity of spacing between the channels. The crests, of course, rise toward the headwaters of the basins which they separate, but where a considerable field is incised in this manner the nodal points of the drainage remain approximately at the same hight above the baselevel.

\section{Bearing of Evidence on Baseleveling}

\section{RELATION OF DOWN-WEARING TO UNIFORMITY OF LEVEL}

At first sight it may seem that this identity of attitude of the remaining highlands in the system of miniature valleys is due to the original equality of the surface on which the work of erosion began. Observations show, however, that even where there is a great variety in elevation the process of down-wearing tends to bring the varied levels into uniformity. In the small scale, rapidly forming drainage this action is more easily recognized than it is in the case of true river basins. The process may indeed be seen in actual operation. Where there are considerable elevations their slopes are steeper and erosive work goes on upon them much more speedily than elsewhere, until their declivities are brought down to the uniform grade of the slopes which the material takes with. a given measure of rainfall. The important point is to discern that an approach to uniformity of interval and lateral slopes of valleys effectively tends to bring about a likeness in the hight of the divides even where the original surface was of varied elevation.

\section{BASELEVELS OF THE APPALACHIANS}

To apply this principle to the matter of ancient baselevels, let us take what is a most characteristic instance, that of the Appalachians. As re- 
gards this region a common hight of summits over large areas has been explained by the supposition that at one or more stages in the history of the area the mountain-built rocks have been worn down to or near their baselevel of erosion, subsequently elevated, and thereafter subjected to the stream erosion which has carved out the existing reliefs.* Considering first the general character of this field as regards the hight of its elevation, we note that, despite the variations in the resistance to erosion, there are sundry parts of it in which the elevation of the highest ridges and peaks are tolerably uniform, so much so indeed as to make the supposition of an ancient baselevel a good working hypothesis. Thus in the hills of Nova Scotia, in the Green mountains and their southern extensions in the Berkshire hills, and in the Alleghanies as far as Alabama we find accordant hights which at first sight appear to be readily explained by the supposition that the erosive work began after the areas had been brought to near the baselevel and afterward uplifted to a hight not far above that which the existing crests attain. For the purpose of our inquiry it will be well to begin with the Alleghanian district, taking account of the areas to the east, including the Blue Ridge mountains and the Piedmont area. More than any other known to me, this field of the southern Appalachians affords good data for discussing the problem in hand.

The features of the area above designated which first claim attention in the inquiry are, first, the tolerably accordant levels of the Alleghany section with hight, which in a general way decline from near Cumberland gap to the plain of southern Alabama; next the presence of a great valley or system of valleys on the western side of the Blue Ridge; then the rise to the southward of the Blue Ridge in the Smoky mountains, and, lastly, the uniform eastward sloping plateau of the Piedmont area, composed of highly metamorphic mountain-built rock, presumably of Cambrian or of Archean, but containing many areas of Mesozoic folded strata. These three mountainous elements of the Appalachians I have for convenience termed the western, the central, and the eastern divisions of that great system. The central is the oldest in the order of formation, owing its existence in part to orogenic actions which probably occurred before the beginning of the Cambrian age. The western or Alleghanian was dislocated nearly at the close of Paleozoic time. The eastern or Piedmont was in large part mountain-built after the close of the Jurassic period, though it doubtless shared with the Blue Ridge mountains in the much earlier disturbance to which it owes its structure.

* For admirable presentations of this view see Arthur Keith : Geology of the Catoctin Belt, 14th Ann. Rep. U. S. Geological Survey, p. 293 et seq.; also, Hayes (Willard) and Campbell (Marius R.): Geomorphology of the Southern Appalachians, National Geographic Mag., vol, vi, p. 63 et seq. 
For this inquiry the most important contrast in the fields above mentioned is in the measure of their degradation, their hight above the sea, and the form of their reliefs. Considered in a general way, it is evident that the Green Mountain district, embodying the Berkshire hills and the Alleghanies, may be, as regards their altitude, not unreasonably grouped together, their hights being in the whole similar, the peaks which surpass an altitude of about 2,000 feet being rather exceptional, and perhaps explainable on the theory that they are due to local resistance to downwearing action. So, too, the Piedmont area, where the slope rises from tidewater westward to the level of about 1,000 feet, exhibits much uniformity in the hight of the crests at equal distances from the central Appalachians, but with many " monadnocks" or steep, isolated peaks rising far above the general plane of crest altitude. In the central section there is, in my opinion, no such accordance in the hights that point to baseleveling followed by elevation, the range in elevation being from about 1,000 feet in New Jersey to about 7,000 feet in North Carolina. There are what might be taken as signs of a progressive rise of these elevations to the south ward were it not that from the Smoky mountains of North Carolina there is a steep decline toward the gulf of Mexico, as well as a rise from New Jersey northward in ridges of related age, culminating in the White mountains of New Hampshire.

Taking first the Alleghanian field we find that the measure of accord in its summit levels is not what it seems at first sight to be. Looking from any summit which com mands a wide prospect, the observer is always struck with the apparent regularity of the skyline of the distant mountains. On close study of this impression, however, he finds reasons to doubt its validity. It is easy to see that at a distance of, say 40 miles, differences of hight of 500 or even of 1,000 feet are not conspicuous unless the additional elevation have a peaked shape. If the rise is gentle at either end it is classed with the prevailing skyline formed by the other ridges. It is only by the careful inspection of good maps which by contours indicate the hights that an adequate conception of the altitudes of the reliefs can be gained. Until within a few years the hights of the Alleghanies were not enough known to afford a basis for this accurate inquiry. At present, however, the topographical maps of the area made by the United States Geological Survey are sufficiently accurate for the purpose. From them we learn that the range in the hights of the crests is considerable, amounting to as much as one-third of the maximum altitude above the plane of the sea, and to as much as one-half the hight to which the crests rise above the plane to which the greater rivers have cut down their channels. It these differences were presented to the eye in a group of peaks brought 
close together the hight relations of their summits would no more suggest the existence of an ancient elevated baselevel than do those of the Swiss Alps. It is rather the long, even skylines of their ridges than their likeness in hight that so distinctly suggests their origin in an elevaled plain.

\section{Problem of Appalachian Bashleveling}

There are two sections of the Alleghany district which are especially noteworthy in this inquiry: One of them is the area about Cumberland gap, especially in the section adjacent to the headwaters of Cumberland river; the other in the drainage of the upper James river near Buffalo. gap. In the first named area is an extensive tract of country where the ridges attain a hight of about 3,000 feet, rising to a considerable elevation above the neighboring crests. It is evidently a case where the superior hight is to be accounted for by the fact that we have there the node whence a number of streams radiate, flowing outwardly with a relatively slight fall, so that their cutting power is not great. In the second case, that near Buffalo gap, the excessive hight of Elliots knob is evidently due to its peculiar structure, which, in the absence of a strong attack by streams, has failed to go down as rapidly as the neighboring crests. These are but two instances out of many which go to show that the wide discrepancies in hight which exist in this region can be explained by variations in the conditions of down-cutting rather than by any reference to the problem of the original plane in which the erosion began.

We may fitly ask certain questions of those who hold to the hypothesis of an ancient elevated baselevel on which the erosion of the Alleghany section began. The first of these concerns the probable hight of the ancient surface above the present summits of the region. It is evident that it must have been very much above the plane of the existing crests. There are probably few geologists who would reckon the period in which this part of the Appalachian has been subjected to erosion since the Mesozoic period, when the supposed elevation took place, at less than ten million years, or the rate of down-wearing at less than 1 foot in 2,000 years. On this computation the original surface must have been 5,000 feet above the summits of the existing crests. Even if we halve this estimate we still leave the supposed plane very far up in the air-so far up indeed, that it does not seem reasonable to assume its sometime existence to account for the slight measure of uniformity which exists in the hights of the existing crests.

The evident difficulties of the view that holds for a baselevel control of the Alleghany ridges are increased when we come to consider the con- 
ditions of the country to the eastward. The Blue Ridge element of the Appalachian system is, as regards the hight of its peaks, even more irregular than the Alleghanies. While the last-named mountains exhibit a general decline to the southward, varied by a few remaining high points, the central ridge irregularly gains in altitude until the greatest hight is attained, in the western part of North Carolina. Yet it must be assumed that this portion of the Appalachian land was as much subjected to the baseleveling actions as the Alleghany area could have been. Its rocks, though harder, are more homogeneous than are the stratified beds on the west, and are, moreover, of a nature more readily to yield to chemical decay. Why, then, should baseleveling have been so effective in the district less than 40 miles to the west and failed to take effect here?

The question just above asked again comes before us when we examine the Piedmont area. We there find rocks in general character much like those of the Blue Ridge, together with newer strata essentially of Triassic age, which have been folded and faulted down into them, have been worn away until the mass forms a broad, rather uniform, field sloping gently from the hight of about 1,000 feet to beneath the level of the sea. So far as our knowledge of this and other continents goes, this area is in aspect one of the most characteristically baseleveled areas that is known, for in it an originally strong mountain topography, where rocks of exceedingly varied resistance are intimately commingled, have over a wide field been reduced to a nearly uniform surface, having a gentle inclination seaward. It is true that here and there isolated peaks surpass this plain, attaining to hights of several hundred feet above it; but although these features have a value in the interpretation, they in nowise deprive the district of its baseleveled character. Yet it appears impossible to explain the level surface of this area on the hypothesis that it has been worn down by river and atmospheric action. We can not apply this explanation, for the reason that the plain passes abruptly into the Blue Ridge, which rises above it to a hight from a few hundred feet in the Potomac valley to about 7,000 feet in North Carolina. It seems to me questionable whether any form of the baseleveling hypothesis will alone or even mainly account for this contrast in the character of the surface of these level and mountainous areas. So far as I can see, the only way in which the facts can be reconciled with that hypothesis is by the further supposition that the Blue Ridge has been separated from the Piedmont area by relatively recent faulting which has lifted the mountainous country to its high level. It is necessary to assume that this action took place after the baseleveling of the seaboard district was effectively accomplished. It is also to be noted that there is no evidence going to 
show that any such sufficient faulting has occurred. 'There are, it is true, abundant faults to be observed in the approximately level district of the shore belt, but these dislocations have had all traces of their original relief completely effaced. Moreover, the passage of the plain to the hills, although accomplished within a narrow belt, is in a measure gradual, showing no signs of sudden change such as would be exhibited if the conditions had been brought about by faulting alone.

It has been suggested that while the Piedmont district remains at or near its Cretaceous baselevel the country to the westward has been so differentially uptilted that the highest point of elevation is the Alleghanian field. To this hypothesis it may be answered that there is a lack of evidence sufficient for its support. The only point where I have been able to find any features which could be taken to afford such evidence is in the section of the James River canyon from the base of the Piedmont plain through the Blue Ridge and into the Alleghany field. The occurrence of many rapids in the lower reaches of James river suggests an uplifting action; but these features go to show that the movement which led to their formation was of relatively very recent age, and that it affected in something like an equal measure all the section from the sea border beyond the axis of the Shenandoah valley.

\section{Discussion of Hypothesis of Baseleveling and of River spacing}

While it can not be maintained that the evidence and arguments set forth in this paper are sufficient to determine a conclusion against the hypothesis of baseleveling as it is used to ex plain the approximate equality of summits throughout a considerably elevated area, it may fairly be claimed that they go to show the need of a more penetrating inquiry into the facts than has yet been essayed. When we consider that the advocates of the hypothesis in question have not yet shown us a region which has been and remains effectively baseleveled; when, moreover, we note that the changes in the relative level of the sea and land are not only frequently extensive, but evidently occur with a speed which is rapid in relation to the rate of down-wearing of the land, we may indeed begin to doubt the validity of the hypothesis that any such wide area as the eastern portion of this continent could ever have been so far worn down throughout its extent as to approach in aspect the supposititious plain which this view demands. There can be no question concerning the value as to the control which a baselevel of erosion exercises over the work of a river. The point yet to be determined relates to the efficiency of river work in bringing about the uniformity of hights in a mountain-built district. It appears to me that in the fields which I 
have been able to examine the effect arising from the interaction of the slopes of rivers spaced with an approximation of equality in interval and with like declivities will more satisfactorily account for the uniformity of elevation than the hypothesis which seeks to explain the coincidence by ancient baseleveling, with subsequent reelevation and denudation. It may well be that in many instances the results of the two groups of actions are intermingled. 


\section{Geological Society of America Bulletin}

\section{Spacing of rivers with reference to hypothesis of baseleveling}

N. S. Shaler

Geological Society of America Bulletin 1899;10, no.

$1 ; 263-276$

doi: 10.1130/GSAB-10-263

Email alerting services

Subscribe

Permission request click

www.gsapubs.org/cgi/alerts to receive free e-mail alerts when new articles cite this article

click

www.gsapubs.org/subscriptions / to subscribe to Geological Society of America Bulletin

click

http://www.geosociety.org/pubs /copyrt.htm\#gsa to contact GSA

(C) 1899 Geological Society of America

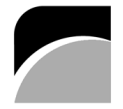

THE GEOLOGICAL SOCIETY OF AMERICA 
Copyright not claimed on content prepared wholly by U.S. government employees within scope of their employment. Individual scientists are hereby granted permission, without fees or further requests to GSA, to use a single figure, a single table, and/or a brief paragraph of text in subsequent works and to make unlimited copies of items in GSA's journals for noncommercial use in classrooms to further education and science. This file may not be posted to any Web site, but authors may post the abstracts only of their articles on their own or their organization's Web site providing the posting includes a reference to the article's full citation. GSA provides this and other forums for the presentation of diverse opinions and positions by scientists worldwide, regardless of their race, citizenship, gender, religion, or political viewpoint. Opinions presented in this publication do not reflect official positions of the Society.

\section{Notes}

(C) 1899 Geological Society of America 